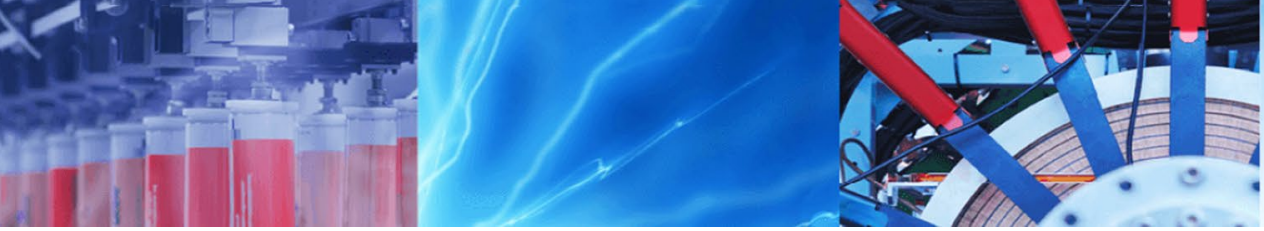

Research Article

\title{
Designing a novel chitosan-based periofilm containing metronidazole-ciprofloxacin
}

\author{
Anahita Azadi Boroujeni ${ }^{1} \cdot$ Mohammadreza Talebi Ardakani $^{2} \cdot$ Behzad Houshmand $^{2} \cdot$ Anahita Moscowchi $^{2}$
}

Received: 14 November 2019 / Accepted: 27 February 2020 / Published online: 5 March 2020

(c) Springer Nature Switzerland AG 2020, corrected publication 2020

\begin{abstract}
Periodontitis is the most common periodontal disease. Because of its infectious-inflammatory nature, as well as the difficulty of complete elimination of pathogens from oral cavity, antibiotics have been proposed as adjunctive modalities to control the disease and prevent its recurrence. Systemic antibiotics could lead to a further reduction in probing depth and bleeding on probing. Nowadays, due to their side effects and the emergence of resistant strains of bacteria, there is a tendency to use local antibiotic delivery systems. The aim of this study was to design, develop and test a mucoadhesive film based on chitosan/gelatin containing metronidazole and ciprofloxacin. A mucoadhesive film containing $2 \%$ chitosan and gelatin and $0.2 \%$ of metronidazole and ciprofloxacin was made by casting method. Laboratory evaluations including drug-releasing pattern through HPTLC, mucoadhesive strength, stability in phosphate buffer, degradation in lysozyme, and water absorption were performed. The results of this study showed that the produced periofilm releases the antibiotics up to $48 \mathrm{~h}$ in concentrations higher than MIC. In the presence of lysozyme, a sharp decline in stability observed in the first 4 days, reached to a constant level after seven days. Based on the results of the present study, it could be concluded that applying the proposed system and its drug combination can be a part of the adjunctive periodontal treatment on a daily basis or every $48 \mathrm{~h}$. However, further studies are needed to recommend this system as a routine therapeutic modality.
\end{abstract}

Keywords Chitosan $\cdot$ Ciprofloxacin $\cdot$ Metronidazole $\cdot$ Mucoahdesive

\section{Introduction}

Chronic periodontitis is a prevalent polymicrobial condition [1], and non-surgical interventions to remove bacterial plaque are the main phase in its management. However, invading the underlying tissues, some microorganisms have the potential to serve as a reservoir to induce recurrent or refractory periodontitis [2]. Moreover, considering the studies carried out on extracted teeth, calculus may remain in deep subgingival pockets, especially in posterior region [3]. Clinical studies have shown that only in $11 \%$ of cases calculi and biofilms are completely removed from tooth surfaces after scaling and root planning [4, 5], which makes periodontal surgery inevitable in some instances. Also, several long-term studies have shown that even open flap debridement has not been efficient enough in removing all irritants [6].

Although laser [7], photodynamic therapy [8, 9], and hyperbaric oxygen [10] have been proposed as adjunctive therapeutic modalities, there is a lack of definitive clinical evidence on their efficacy [11]. Antimicrobial agents have been proven to efficiently complement mechanical debridement in patients with moderate-to-severe periodontitis [12]. Metronidazole is an effective agent in the

$\triangle$ Behzad Houshmand, houshmandperio@rocketmail.com | ${ }^{1}$ Department of Periodontics, School of Dentistry, Kashan University of Medical Sciences, Kashan, Iran. ${ }^{2}$ Department of Periodontics, School of Dentistry, Shahid Beheshti University of Medical Sciences, Tehran, Iran. 
treatment of chronic, aggressive and necrotizing periodontitis [13]. Ciprofloxacin has also been used in combination with metronidazole in the treatment of periodontal disease and its efficacy and safety has been confirmed [11]. However, prescription of systemic medications does not seem logical due to side effects and lack of site-specificity. Two recent reviews suggested that local antibiotics resulted in a decrease of $0.6 \mathrm{~mm}$ in probing depth and $0.3 \mathrm{~mm}$ attachment gain compared to conventional treatment. In addition, no specific systemic complications have been reported $[14,15]$. These systems have some drawbacks including short-term effects and inadequate penetration into the periodontal pockets. Therefore, recent studies have focused on sustained release drug delivery systems [16-19]. Using a mucoadhesive paste for local release of medications has several important biologic advantages including longer release, intimate contact, increased bioavailability, and specific targeting $[20,21]$.

Chitosan is a linear polysaccharide and copolymer. It has been known as a compatible material with various applications in biotechnology and medical engineering due to lack of toxicity and biodegradability. On the other hand, pure chitosan has bactericidal effects. Consequently, these promising properties have made it a favorable candidate for controlled release of medications [22]. Gelatin is a biodegradable and biocompatible polymer of type I collagen. Its favorable properties including biocompatibility, low immunogenicity, plasticity, promotion of cellular adhesion and growth, and low cost have made it an ideal biomaterial [23, 24].

Considering the promising results of local antibiotics and favorable properties of aforementioned biomaterials, this study designed to develop and test a chitosan/ gelatin mucoadhesive paste loaded with metronidazole and ciprofloxacin as an adjunctive method to conventional periodontal interventions.

\section{Material and methods}

The following materials used to prepare the chitosan/gelatin composite:

- Chitosan with moderate molecular weight (medical grade) (Sigma, St. Louis, USA).

- Microbiologic type of gelatin (medical grade) (Merck, Netherlands).

- Glycerol at $80 \%$ concentration (medical grade) (Merck, Netherlands).

- Acetic acid (Merck, Netherlands).

- Ciprofloxacin hydrochloride (Fluka, Hannover, Germany).

- Metronidazole (Sigma, St. Louis, USA).

\subsection{Antibiotic incorporation}

Initially, the antibiotic concentration of $1 \mathrm{wt} \%$ was selected, but unfortunately it did not dissolve in the polymer. Therefore, after laboratory evaluations, three antibiotic wt\% $(0.2,0.4$, and 0.6$)$ were determined as optimal percentages. A proper amount of each antibiotic (ciprofloxacin and metronidazole) was added to gelatin. After $3 \mathrm{~h}$ of mixing on a stirrer, the solution was transferred to a decanter.

\subsection{Preparation of chitosan/gelatin composite}

Chitosan and gelatin ( $2 \mathrm{wt} \%$ ) were dissolved in $1 \%$ acetic acid and distilled water, respectively. To improve plasticity, $25 \mathrm{wt} \%$ glycerol was added to each solution and they were placed on a heater/stirrer ) $300 \mathrm{rpm}, 50^{\circ} \mathrm{C}$ ) for $1-2 \mathrm{~h}$ in order to achieve a homogeneous solution. Subsequently, centrifugation (4000 rpm) was carried out for $30 \mathrm{~min}$ to purify the viscous chitosan solution, and gelatin was prepared using Whatman filter paper (\#42).

The optimal chitosan/gelatin ratio was estimated at $3: 1$. After mixing the two polymers in a decanter at $50^{\circ} \mathrm{C}$ for two hours using a magnetic mixer (300 rpm), $24 \mathrm{ml}$ of the resultant material was placed on a plastic petri dish to prepare the mucoadhesive film using casting method. It should be noted that the $\mathrm{pH}$ value of the resultant solution was adjusted at 5-5.5 using $1 \mathrm{~mol}$ of $\mathrm{NaOH}$ in order to bring about the necessary reaction between chitosan and gelatin.

The films were dried at room temperature for $2-3$ days. They were placed in a container under controlled condition (moisture content of $60-65 \%$ and $23 \pm 2{ }^{\circ} \mathrm{C}$ temperature for at least $48 \mathrm{~h}$ ) prior to further assessments.

\subsection{The following tests were conducted}

\section{Turgescence and water absorption}

Three samples of biofilms $(1 \times 1 \mathrm{~cm})$ were weighed using digital scale to obtain the initial dry weight of each sample. The samples were reweighed after incubation for $24 \mathrm{~h}$ in $15 \mathrm{ml}$ of synthetic saliva (KinHydrate, $\mathrm{pH}$ 6.8) in the bainmarie $\left(37^{\circ} \mathrm{C}\right)$. The water absorption and turgescence percentages of the samples were calculated using the following equation:

$\%$ Sw or Wuptake $=\frac{w w-w d}{w^{\prime} d}$ 
In the above equation, "wd" and "ww" are the film weight in the dry and in the swelling state, respectively. After $24 \mathrm{~h}$ remaining in artificial saliva followed by using filter paper, the biofilm was placed in the oven $\left(65^{\circ} \mathrm{C}\right)$ for $4 \mathrm{~h}$ and then in a desiccator for $48 \mathrm{~h} \mathrm{("w'd"} \mathrm{is} \mathrm{the} \mathrm{film} \mathrm{weight} \mathrm{after} \mathrm{this}$ process) [25].

2. Stability in phosphate-buffered saline and biodegradability in lysozyme

Samples $(1 \times 1 \mathrm{~cm})$ were initially weighed and then incubated in the bain-marie $(10 \mathrm{ml}$ saline phosphate buffer, $\mathrm{pH} 7,37^{\circ} \mathrm{C}$ ) in the presence or absence of $10^{4} \mathrm{U} / \mathrm{ml}$ lysozyme for a period of 1-7 days. They were reweighed after using filter paper. The percent stability and degradation of the samples were obtained by the following equations:

$$
\begin{aligned}
& \% S T=\frac{w t}{w 1} \times 100 \\
& \% B D=\frac{w 1-w t}{w 1} \times 100
\end{aligned}
$$

In the above equation, $w 1$ and wt are equal to the initial dry weight and the weight obtained after time " $\mathrm{t}$ ". It should be noted that after each sample removal, the previous buffer solution was replaced with a fresh one to minimize the error [26].

3. Ciprofloxacin and metronidazole release pattern via high performance thin layer chromatography (HPTLC)

Initially, $30 \times 7 \mathrm{~mm}$ samples of films were prepared (three samples of each antibiotic concentration). They were placed in $10 \mathrm{ml}$ phosphate buffer solution and incubated at $37^{\circ} \mathrm{C}$. Five milliliter of samples were collected every one hour and were placed in $10 \mathrm{ml}$ of new phosphate buffer solution resulting from the addition of $1 \mathrm{ml}$ of the previous solution and $9 \mathrm{ml}$ of the new one in order to mimic the oral environment. The specimens were stored in a refrigerator at $4{ }^{\circ} \mathrm{C}$ and evaluated using the following protocol:

- Stationary phase: HPTLC Plate (Silica gel $60 \mathrm{~F} 254$ glass $20 \times 10 \mathrm{~cm}$ ).

- Sample application: Camag Automatic TLC Sampler 4; $10 \mu \mathrm{l}$ ( two times).

- Mobile phase: Methanol, Acetonitrile (2:1).

- Development: Camag Horizontal chamber $(20 \times 10 \mathrm{~cm})$.

- Evaluation: Camag TLC Scanner 3; $295 \mathrm{~nm}$ wavelength.

- Imaging system: Camag Visualizer.

\section{Measurement of adhesion force}

When an oral mucoadhesive paste patch is designed, its adhesion to the buccal mucosa for a few hours should be guaranteed. Measurement of adhesion force using sheep mucosa has been accepted as a standard. Animal mucosa was prepared by separation of connective tissue from the mucosal layer (3-4 mm thickness). After rinsing with phosphate buffer ( $\mathrm{pH} 7.4)$, the mucous membrane was attached to a fixed $15 \mathrm{~mm}$ diameter disc. The paste was attached to another disc with the same diameter, which was connected by a string to a scale. The periofilm was placed on the mucosal surface for $120 \mathrm{~s}$ and then deattached $(0.5 \mathrm{~mm} / \mathrm{s})$. The force at which the periofilm was separated from the mucosa was recorded as the adhesion force $[25,27]$.

\section{Measurement of the mucoadhesive film durability}

The sheep mucosa was removed from the underlying connective tissue. It was placed on a fixed $15 \mathrm{~mm}$ circular disc. Periofilm were attached to discs of the same diameter. Each periofilm was kept on the mucosa for $120 \mathrm{~s}$ and the durability under determined force was recorded $[25,27]$.

\section{Results}

The results showed that stability in phosphate-buffered saline decreased during the first 4 days. The biodegradability in lysozyme was high during this period, decreased subsequently, and remained stable afterwards (Figs. 1, 2).

The water sorption and turgescence of mucoadhesive paste were estimated at $22.8 \%$ after $24 \mathrm{~h}$, which became stable afterwards (Fig. 3).

The adhesion force of the pastes on the sheep buccal mucosa has been estimated at $3.2 \pm 0.73 \mathrm{~g}$. The durability of chitosan/gelatin composite on the mucosa was calculated at 2:33:579 $\pm 00: 15: 28$ (hh:mm:ss).

Both ciprofloxacin and metronidazole were released in bursts (rapid release in high percentage during a short period). This pattern in the first hour continued at a lower rate during the second hour and then reached a relatively stable state and set at a slow release pattern (Figs. 4, 5).

Ciprofloxacin was released at a rate of more than $1 \mu \mathrm{g} /$ $\mathrm{ml}$ up to $48 \mathrm{~h}$ at all $3 \%$ combinations. Considering metronidazole, only with the $0.2 \%$ combination the related concentration was more than $1 \mu \mathrm{g} / \mathrm{ml}$ for $24 \mathrm{~h}$ and with other percentages reached below the acceptable and detectable levels at 4- and 5-h intervals.

\section{Discussion}

Penetration of periodontal pathogens into the soft and hard tissues, and inadequate elimination of the microbial plaque using therapeutic modalities, make adjunctive 

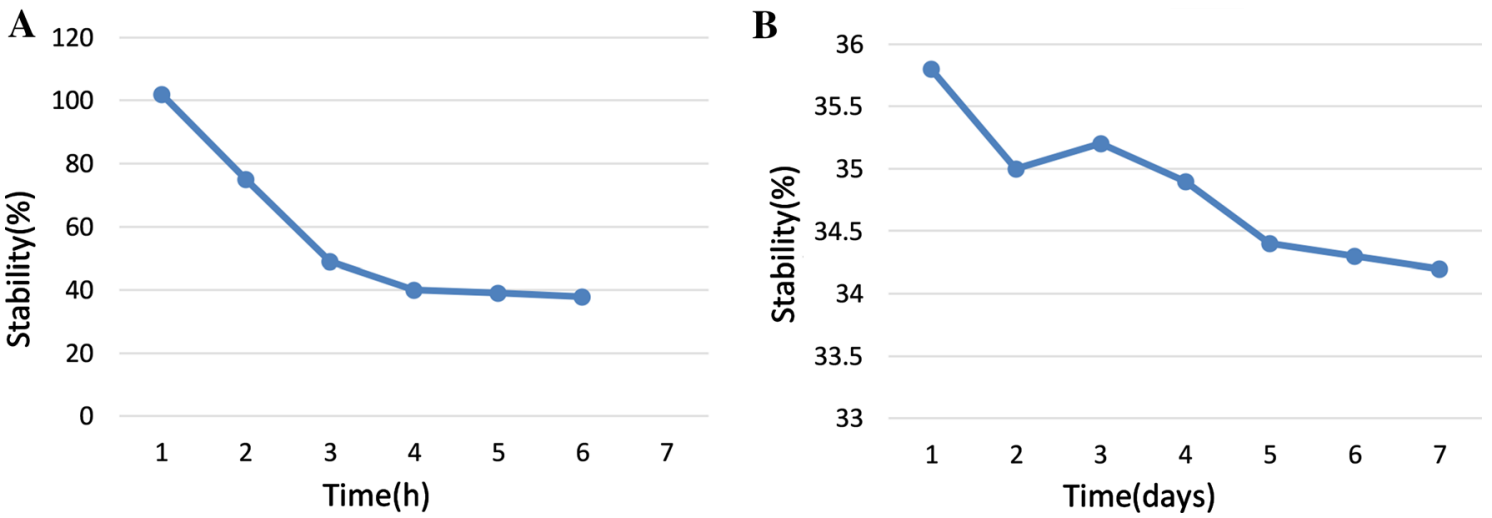

Fig. 1 Stability of the samples in phosphate-buffered saline at 0-6-h and 1-7-day intervals

Fig. 2 Degradation percentages of chitosan/gelatin composite in the presence of lysozyme at a concentration of $104 \mathrm{U} / \mathrm{ml}$ in phosphatebuffered saline at $0-6-h$ (a) and 1-7-day (b) intervals
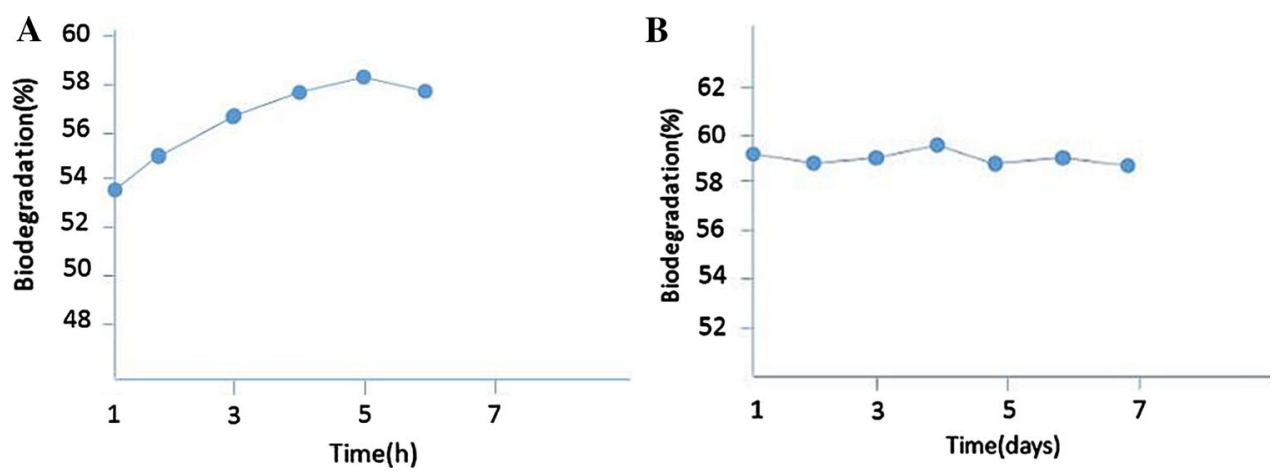

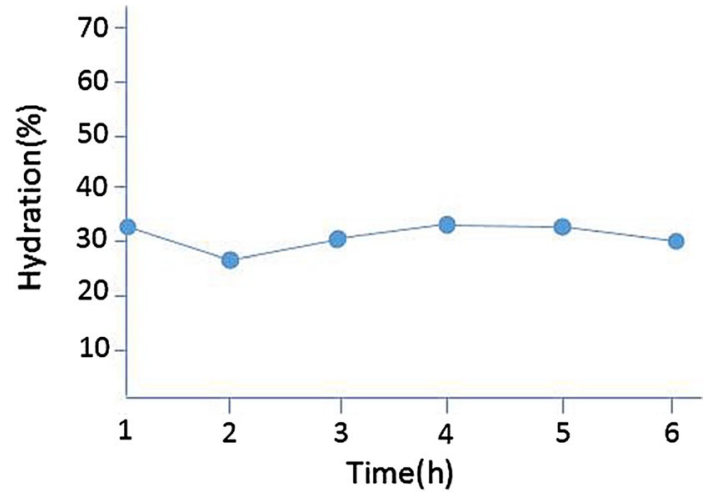

Fig. 3 Water sorption percentages (turgescence percentages) of the samples at different time intervals $(1,2,3,4,5$ and $6 \mathrm{~h})$

antimicrobial agents as potential means to decrease the need for more advanced and costly treatments $[2,3,12$, 28].

Systemic antibiotics have yielded good results as an adjunctive treatment for periodontal diseases $[2,11]$. However, due to their side effects and emergence of resistant microbial species, there is a tendency toward the use of local drug delivery systems. The main disadvantages of the available local delivery systems such as mouth rinses, patches, fibers and gels, are lack of durability, rapid clearing from the site due to the salivary flow and outflow of gingival crevicular fluid, and short bioavailability resulting in inadequate therapeutic efficacy $[11,29,30]$.

To the best of our knowledge, the present study is the first study of producing a mucoadhesive periofilm containing a combination of metronidazole and ciprofloxacin. The first part of this serial qualitative research reports the manufacturing and laboratory evaluation of the mucoadhesive paste.

The results in relation to the release of medications in a phosphate-buffered environment showed that both medications were released in bursts and the doses of ciprofloxacin and metronidazole during the first 24 and $48 \mathrm{~h}$ were higher than the mean inhibitory concentration (MIC). El-Kamel et al. [23] tested a mucoadhesive film based on $1 \%$ chitosan using cross-linked polycaprolactone, which contained metronidazole and reported released concentration of over $1 \mu \mathrm{g} / \mathrm{ml}$ up to $6 \mathrm{~h}$. Given a lack of crosslinking in the present study, an improvement in the release of medicines might be attributed to a higher concentration of chitosan [29]. As will be discussed in the following section, a higher concentration of chitosan results in 
Fig. 4 The graphs in relation to the release of ciprofloxacin (a) and metronidazole $(\mathbf{b})$ at three percentage combinations
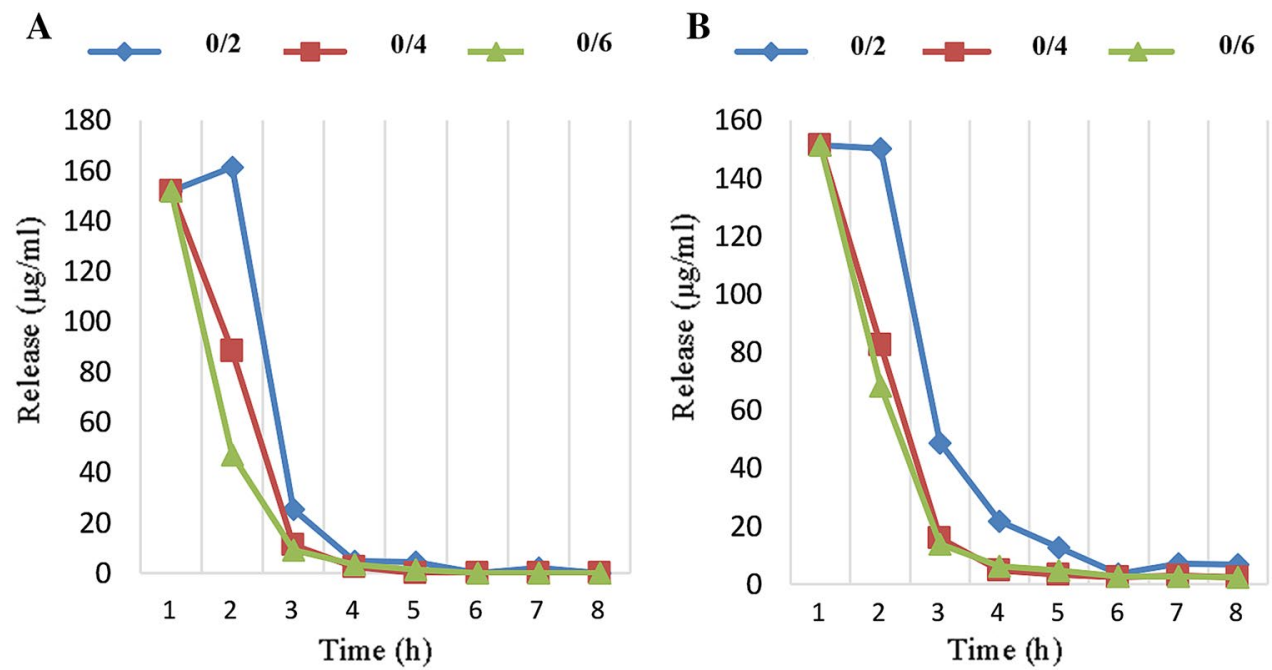

A

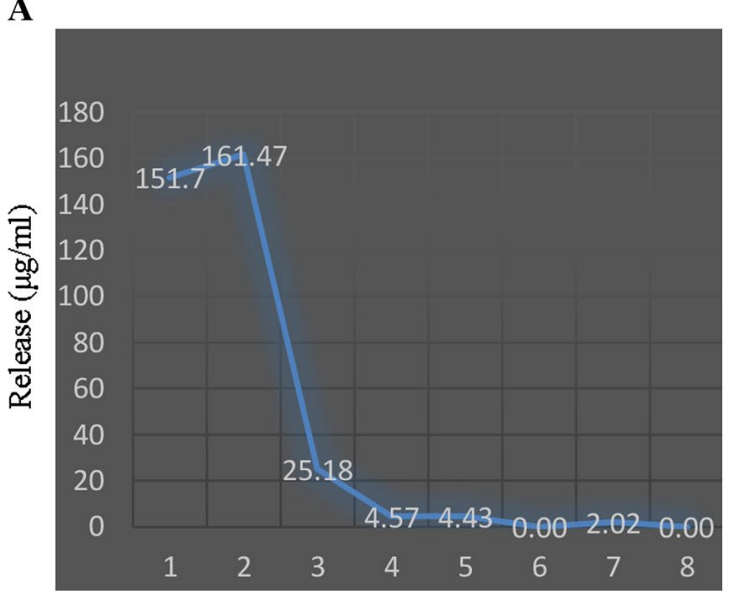

Time (h)
B

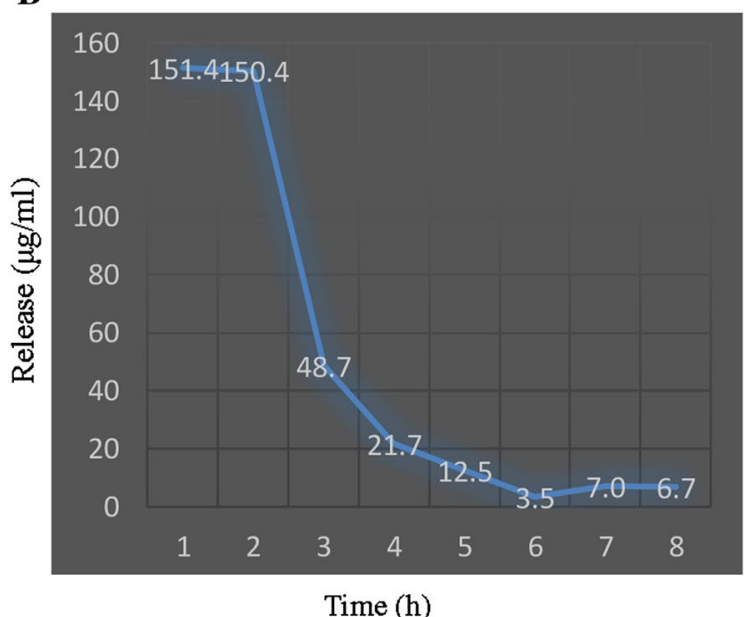

Fig. 5 Ciprofloxacin (a) and metronidazole (b) release pattern in $0.2 \%$ concentration

a decrease in water sorption and the turgescence of the system and also solubility, resulting in an improvement in the physical properties. However, it should be pointed out that an excessive increase in chitosan percentage could exert unwanted effects. Based on a previous study by the same group, the optimum percentage of chitosan was determined at $2 \%[20,31]$.

Labib et al. [32] evaluated mucoadhessive films containing chitosan and metronidazole. Similar to our study their system lacked cross-linking. The results showed a burst pattern and a high percentage of the medicine was released during the first $2 \mathrm{~h}$, followed by a significant decrease, almost consistent with the results of the present study.

One of the first studies on the local delivery of ciprofloxacin using a chitosan polymer system was carried out by Orhan in 2006 [33] for osteomyelitis with $1 \%$ of chitosan and drug-to-chitosan ratio of 1:1. The drug release pattern had a burst pattern during the first days, and after $120 \mathrm{~h} 36 \%$ of the drug had been released. However, in the present study, after $48 \mathrm{~h}$ the whole medication had been released from the paste. Given the low concentration of chitosan, such a difference might be attributed to the increased initial concentration of the medicine in the relevant system.

Unfortunately, no study was found on the simultaneous use of ciprofloxacin and metronidazole in a polymer base. The only study brought up by extensive search was that of Bottino in 2014, in which no polymer was used and the two medications had been incorporated into an absorbable suture material as a vector [19].

In a study somehow similar to the present one in 2014, a combination of ofloxacine and $2 \%$ chitosan without crosslinking was used to treat ocular infections. Interestingly, 
the results showed that the concentration of the released medication was higher than MIC for 7 days and the release pattern was relatively gradual [34].

Evaluation of the properties of the proposed film showed an adhesive force of approximately $4 \mathrm{~g}$, which persisted for 2 days. Although hydrophilic macromolecules such as chitosan have exhibited mucoadhesive paste properties, excessive turgescence of these molecules can result in the formation of a non-adhesive slippery layer on the mucosa, limiting their application [35].

Previous studies have shown that a large amount of gelatin decreases the mucoadhesive properties of chitosan/gelatin composite due to its reaction with the amine groups of chitosan and formation of a film with a high rate of turgescence. In fact, it has been reported that a higher percentage of chitosan, due to the positive charge of its chains, can react with the sialic acid and sulfate glycoproteins of the mucosa in the oral cavity that have a negative charge. Therefore, the mucoadhesive force found in chitosan/gelatin film might be attributed to such a phenomenon [36]. Given this fact and based on a previous study by this group, the optimal ratio of chitosan/gelatin was considered 3:1.

As a polymer that can maintain its structure in the presence of water, one of the important factors is the water absorption. Another important factor is the type of the polymer and the homogeneity of the mixture. Some researchers have reported that the physical and chemical properties of the polymer do not have a significant effect on the longevity of the polymer on the mucosa [25]. In addition, some studies have shown that there is no relationship between mucoadhessive paste longevity and its adhesive force, and highly adhesive polymers will not necessarily remain for a longer period. Although the surface load density and flexibility of the chain are important factors for the adhesive force to the mucosa, the durability depends on the polymer solubility in the first place [27]. Moreover, water sorption and relatively high turgescence rate of this polymer might exert negative effects on the other physical properties, including stability in phosphatebuffered solution, biodegradability within lysozyme, and fragmentation [20,35].

It appears one of the main problems of this study was the absence of cross-linking in the system. In the majority of previous studies on local delivery systems, a crosslinking agent has been incorporated into the chitosan system. Different researchers have used different materials for cross-linking [23, 37-39]. The most commonly used material is glutaraldehyde, which has yielded favorable results. The main advantage of this technique is trapping the chitosan molecules and better management of water absorption, and as discussed above, when these factors decrease up to optimal levels, the physical properties of the system improve. However, due to the toxic nature of glutaraldehyde, it is less commonly used at present [40, 41]. Therefore, a decision was made not to use glutaraldehyde and not incorporate cross-linking in the present study. Since it is possible to easily replace the prepared film daily or every $48 \mathrm{~h}$, this problem cannot exert a negative effect on the system.

\section{Conclusions}

Based on the results of the present study, application of the proposed system and its drug combination can be a part of the adjunctive periodontal treatment on a daily basis or every $48 \mathrm{~h}$. However, further studies are needed to recommend this system as a routine therapeutic modality.

Future studies could be focused on the following objectives:

- Use of a nontoxic cross-linking agent.

- Evaluation of the efficacy of the film in eliminating microorganisms in vitro.

- Evaluation of the efficacy of the film in animals (ex vivo).

- Evaluation of the efficacy of the film in humans through controlled clinical trials.

\section{Compliance with ethical standards}

Conflict of interest The authors declare that they have no conflict of interest related to this study.

Humans and animal rights Moreover, no experiments performed on animals or humans during this investigation.

\section{References}

1. Bonito AJ, Lohr KN, Lux L, Sutton S, Jackman A, Whitener L et al (2004) Effectiveness of antimicrobial adjuncts to scaling and root-planing therapy for periodontitis. Evid Rep Technol Assess (Summ) 88:1-4

2. Mombelli A, Cionca N, Almaghlouth A (2011) Does adjunctive antimicrobial therapy reduce the perceived need for periodontal surgery? Periodontol 2000 55(1):205-216. https://doi.org/1 0.1111/j.1600-0757.2010.00356.x

3. Haffajee AD, Socransky SS, Gunsolley JC (2003) Systemic anti-infective periodontal therapy. A systematic review. Ann Periodontol 8(1):115-181. https://doi.org/10.1902/annal S.2003.8.1.115

4. Stambaugh RV, Dragoo M, Smith DM, Carasali L (1981) The limits of subgingival scaling. Int J Periodontics Restor Dent 1(5):30-41 
5. Waerhaug J (1978) Healing of the dento-epithelial junction following subgingival plaque control. II: As observed on extracted teeth. J Periodontol. 49(3):119-134. https://doi.org/10.1902/ jop.1978.49.3.119

6. Petersilka GJ, Ehmke B, Flemmig TF (2000) Antimicrobial effects of mechanical debridement. Periodontol 2002(28):56-71

7. Schwarz F, Aoki A, Sculean A, Becker J (2000) The impact of laser application on periodontal and peri-implant wound healing. Periodontol 2000 2009(51):79-108. https://doi.org/10.111 1/j.1600-0757.2009.00301.x

8. Fontana $C R$, Abernethy $A D$, Som $S$, Ruggiero $K$, Doucette $S$, Marcantonio RC et al (2009) The antibacterial effect of photodynamic therapy in dental plaque-derived biofilms. J Periodontal Res 44(6):751-759. https://doi.org/10.111 1/j.1600-0765.2008.01187.x

9. Novaes AB Jr, Schwartz-Filho HO, de Oliveira RR, Feres M, Sato $S$, Figueiredo LC (2012) Antimicrobial photodynamic therapy in the non-surgical treatment of aggressive periodontitis: microbiological profile. Lasers Med Sci 27(2):389-395. https://doi. org/10.1007/s10103-011-0901-6

10. Nogueira-Filho GR, Rosa BT, David-Neto JR (2010) Effects of hyperbaric oxygen therapy on the treatment of severe cases of periodontitis. Undersea Hyperb Med 37(2):107-114

11. Slots J (2012) Low-cost periodontal therapy. Periodontol 2000 60(1):110-37. https://doi.org/10.1111/j.1600-0757.2011.00429 .$x$

12. Slots J (2002) Selection of antimicrobial agents in periodontal therapy. J Periodontal Res 37(5):389-398

13. Ings RM, McFadzean JA, Ormerod WE (1974) The mode of action of metronidazole in Trichomonas vaginalis and other microorganisms. Biochem Pharmacol 23(9):1421-1429. https://doi. org/10.1016/0006-2952(74)90362-1

14. Bonito AJ, Lux L, Lohr KN (2005) Impact of local adjuncts to scaling and root planing in periodontal disease therapy: a systematic review. J Periodontol 76(8):1227-1236. https://doi. org/10.1902/jop.2005.76.8.1227

15. Hanes PJ, Purvis JP (2003) Local anti-infective therapy: pharmacological agents. A systematic review. Ann Periodontol 8(1):7998. https://doi.org/10.1902/annals.2003.8.1.79

16. Nastri L, De Rosa A, De Gregorio V, Grassia V, Donnarumma G (2019) A New controlled-release material containing metronidazole and doxycycline for the treatment of periodontal and peri-implant diseases: formulation and in vitro testing. Int J Dent 2019(5):1-10. https://doi.org/10.1155/2019/9374607

17. Kilicarslan M, Ilhan M, Inal O, Orhan K (2018) Preparation and evaluation of clindamycin phosphate loaded chitosan/alginate polyelectrolyte complex film as mucoadhesive drug delivery system for periodontal therapy. Eur J Pharm Sci 123:441-451. https://doi.org/10.1016/j.ejps.2018.08.007

18. Gjoseva S, Geskovski N, Sazdovska SD, Popeski-Dimovski R, Petrusevski G, Mladenovska K et al (2018) Design and biological response of doxycycline loaded chitosan microparticles for periodontal disease treatment. Carbohydr Polym 186:260-272. https://doi.org/10.1016/j.carbpol.2018.01.043

19. Bottino MC, Arthur RA, Waeiss RA, Kamocki K, Gregson KS, Gregory RL (2014) Biodegradable nanofibrous drug delivery systems: effects of metronidazole and ciprofloxacin on periodontopathogens and commensal oral bacteria. Clin Oral Investig 18(9):2151-2158. https://doi.org/10.1007/s00784-014-1201-x

20. Bernkop-Schnurch A, Scholler S, Biebel RG (2000) Development of controlled drug release systems based on thiolated polymers. J Control Release 66(1):39-48

21. Khutoryanskiy VV (2011) Advances in mucoadhesion and mucoadhesive polymers. Macromol Biosci 11(6):748-764. https ://doi.org/10.1002/mabi.201000388
22. Bhattarai N, Gunn J, Zhang M (2010) Chitosan-based hydrogels for controlled, localized drug delivery. Adv Drug Deliv Rev 62(1):83-99. https://doi.org/10.1016/j.addr.2009.07.019

23. El-Kamel AH, Ashri LY, Alsarra IA (2007) Micromatricial metronidazole benzoate film as a local mucoadhesive delivery system for treatment of periodontal diseases. AAPS Pharm Sci Tech 8(3):E75. https://doi.org/10.1208/pt0803075

24. Wang Y, Qiu D, Cosgrove T, Denbow ML (2009) A small-angle neutron scattering and rheology study of the composite of chitosan and gelatin. Colloids Surf B Biointerfaces 70(2):254-258. https://doi.org/10.1016/j.colsurfb.2008.12.034

25. Perioli L, Ambrogi V, Angelici F, Ricci M, Giovagnoli S, Capuccella $M$ et al (2004) Development of mucoadhesive patches for buccal administration of ibuprofen. J Control Release 99(1):73-82. https ://doi.org/10.1016/j.jconrel.2004.06.005

26. Jiankang $\mathrm{H}$, Dichen $\mathrm{L}$, Yaxiong $\mathrm{L}$, Bo $\mathrm{Y}$, Hanxiang $\mathrm{Z}$, Qin $\mathrm{L}$ et al (2009) Preparation of chitosan-gelatin hybrid scaffolds with well-organized microstructures for hepatic tissue engineering. Acta Biomater 5(1):453-461. https://doi.org/10.1016/j.actbi o.2008.07.002

27. Nafee NA, Boraie MA, Ismail FA, Mortada LM (2003) Design and characterization of mucoadhesive buccal patches containing cetylpyridinium chloride. Acta Pharm 53(3):199-212

28. Hirschfeld L, Wasserman B (1978) A long-term survey of tooth loss in 600 treated periodontal patients. J Periodontol 49(5):225-237. https://doi.org/10.1902/jop.1978.49.5.225

29. Herrera D, Matesanz P, Bascones-Martinez A, Sanz M (2012) Local and systemic antimicrobial therapy in periodontics. J Evid Based Dent Pract 12(3 Suppl):50-60. https://doi.org/10.1016/s1532 -3382(12)70013-1

30. Mohammadi Z, Abbott PV (2009) On the local applications of antibiotics and antibiotic-based agents in endodontics and dental traumatology. Int Endod J 42(7):555-567. https://doi.org/10. 1111/j.1365-2591.2009.01564.x

31. Lee JW, Park JH, Robinson JR (2000) Bioadhesive-based dosage forms: the next generation. J Pharm Sci 89(7):850-866. https://doi.org/10.1002/1520-6017(200007)89:7\%3c850 :aid-jps2\%3e3.0.co;2-g

32. Labib GS, Aldawsari HM, Badr-Eldin SM (2014) Metronidazole and Pentoxifylline films for the local treatment of chronic periodontal pockets: preparation, in vitro evaluation and clinical assessment. Expert Opin Drug Deliv 11(6):855-865. https://doi. org/10.1517/17425247.2014.897325

33. Orhan Z, Cevher E, Mulazimoglu L, Gurcan D, Alper M, Araman A et al (2006) The preparation of ciprofloxacin hydrochlorideloaded chitosan and pectin microspheres: their evaluation in an animal osteomyelitis model. J Bone Joint Surg Br 88(2):270-275. https://doi.org/10.1302/0301-620x.88b2.16328

34. de Oliveira FG, Viana FA, Silva RO, Lobato FC, Ribeiro RR, Fanca JR et al (2014) Mucoadhesive chitosan films as a potential ocular delivery system for ofloxacin: preliminary in vitro studies. Vet Ophthalmol 17(2):150-155. https://doi.org/10.1111/vop.12140

35. Asane GS, Nirmal SA, Rasal KB, Naik AA, Mahadik MS, Rao YM (2008) Polymers for mucoadhesive drug delivery system: a current status. Drug Dev Ind Pharm 34(11):1246-1266. https://doi. org/10.1080/03639040802026012

36. Abruzzo A, Cerchiara T, Bigucci F, Gallucci MC, Luppi B (2015) Mucoadhesive buccal tablets based on chitosan/gelatin microparticles for delivery of propranolol hydrochloride. J Pharm Sci 104(12):4365-4372. https://doi.org/10.1002/jps.24688

37. Barat R, Srinatha A, Pandit JK, Anupurba S, Mittal N (2007) Chitosan inserts for periodontitis: influence of drug loading, plasticizer and crosslinking on in vitro metronidazole release. Acta Pharm 57(4):469-477. https://doi.org/10.2478/v1000 7-007-0037-1 
38. Mura C, Valenti D, Floris C, Sanna R, De Luca MA, Fadda AM et al (2011) Metronidazole prodrugs: synthesis, physicochemical properties, stability, and ex vivo release studies. Eur J Med Chem 46(9):4142-4150. https://doi.org/10.1016/j.ejmech.2011.06.016

39. Pichayakorn W, Boonme P (2013) Evaluation of cross-linked chitosan microparticles containing metronidazole for periodontitis treatment. Mater Sci Eng C Mater Biol Appl 33(3):1197-1202. https://doi.org/10.1016/j.msec.2012.12.010

40. Kim M, Takaoka A, Hoang QV, Trokel SL, Paik DC (2014) Pharmacologic alternatives to riboflavin photochemical corneal crosslinking: a comparison study of cell toxicity thresholds. Invest
Ophthalmol Vis Sci 55(5):3247-3257. https://doi.org/10.1167/ iovs.13-13703

41. Zeiger E, Gollapudi B, Spencer P (2005) Genetic toxicity and carcinogenicity studies of glutaraldehyde - a review. Mutat Res 589(2):136-151. https://doi.org/10.1016/j.mrrev.2005.01.001

Publisher's Note Springer Nature remains neutral with regard to jurisdictional claims in published maps and institutional affiliations. 